\title{
63. Observations on Geographic and Temporal Variations in the Ladybeetle Harmonia. I Elytral Patterns
}

\author{
By Taku KomaI, M.J.A.*), and Masuho Chino**) \\ (Comm. April 12, 1969)
}

Material. The material is Harmonia axyridis Pallas, one of the commonest ladybeetles in the Orient. It has highly variable markings on the pronotum and elytra. Especially the elytral pattern is distinctly polymorphic, with variable proportions of melanic and orange-red areas. Four main types may be distinguished as conspicua, spectabilis, axyridis, and succinea (Dobzhansky 1933, '37, Hosino 1940, Komai 1956a, b). Breeding experiments by Hosino have shown that these types are controlled by genes in a multiple-allelic series with the order of dominance conspicua $>$ spectabilis>axyridis $>$ succinea, corresponding to the extention of the melanic area. More precisely, the genes are essentially codominant, and the heterozygote may often be distinguished by the shape and size of the pattern and spots. Tan (1948) designated this mode of inheritance as "mosaic dominance". Obviously, this is owing to that the relevant genes are not multiple-allelic in the strict sense, but are rather pseudo-allelic, and the locus is of a composite type (Ford 1964). Each type has minor varieties in the shape of pattern or spot. Even these variants have each a genetic basis (Komai 1956b). This finding suggests a highly composite state of the locus. Obviously these pattern types compose a typical "morphic" series (Huxley 1955).

Geographic variation in pattern types. Nearly 100 population samples of this beetle were obtained from various localities in Japan, from Hokkaido to Kyusyu, as well as from North China, Korea, and Formosa. Studies on the composition of these specimens and their genetic analyses have shown considerable geographic variation in the frequencies of these phenotypes and of the genes controlling them. There is in these features a distinct and regular gradient, "cline", passing from Hokkaido through Kyusyu. Namely, the proportion of the recessive type succinea is largest in populations inhabiting Hokkaido, amounting to $40 \sim 60 \%$. It decreases to $30 \sim 40 \%$ in populations in the north-eastern districts of Honsyu, to $20 \sim 35 \%$ in popu-

*) No. 64, Kitasirakawa-Iorichô, Sakyô-ku, Kyoto.

**) Ina Primary School, Ina-si, Nagano-ken. 
lations in the middle of Honsyu, around $15 \%$ in those in Kyoto-Osaka district, $10 \%$ in Tyugoku-Sikoku districts; the rate drops below 5\% in Kyusyu. The frequency of succinea abruptly rises to $80+\%$ in populations occurring in Korea and North China. Conversely, the proportion of the darkest type conspicua makes an ascending gradient from $30 \sim 40 \%$ in Hokkaido populations to $50 \%$ in Tokyo area, $60 \%$ in Nagoya-Gihu and Sikoku populations, and $80 \%$ in Kyusyu populations. A small collection of the same species was obtained from a locality near Taipei in Formosa. This consisted entirely of conspicua. The percentage of this type abruptly falls below 5\% in populations inhabiting Korea and North China. The corresponding gene frequencies for the pattern types also make a similar gradient from Hokkaido through Kyushu (Komai 1956a, b, Komai et al. 1950).

Another gradient in the Continental China from north to south has been observed (Tan 1949). The proportion of succinea decreases from the $80+\%$ in North China to $66.6 \%$ in Soochow, 18.6 58.5\% in Hanchow, and $42.6 \%$ in Szchewan.

Temporal variation in pattern types.' As shown in our previous reports, a distinct temporal variation in the proportions of succinea and conspicua was observed. The material was population samples collected at Suwa in Nagano Prefecture in the period from 1912 through 1954. Beginning in the sample collected in 1920, a regular change in the proportions of succinea and conspicua had taken place.

Table I A. Frequencies of the genes of elytral patterns in Suwa-Tatuno population for the period 1912-1965

\begin{tabular}{cccccc}
\hline Year & succinea & axyridis & spectabilis & conspicua & Number \\
\hline 1912, '13 & .653 & .034 & .047 & .246 & 2005 \\
1914 & .646 & .042 & .075 & .237 & 1413 \\
1915, '17 & .659 & .035 & .073 & .233 & 2059 \\
$1920(\mathrm{~A})$ & .651 & .033 & .057 & .246 & 4512 \\
$1930(\mathrm{~B})$ & .612 & .031 & .075 & .282 & 13157 \\
$1942,{ }^{\prime} 43(\mathrm{C})$ & .566 & .043 & .098 & .293 & 823 \\
$1950(\mathrm{D})$ & .537 & .033 & .090 & .340 & 2220 \\
$1954(\mathrm{E})$ & .532 & .028 & .099 & .341 & 258 \\
1964, '65(F) & .418 & .052 & .129 & .401 & 911 \\
\hline
\end{tabular}

Table I B. Differences in frequencies of genes for succinea and conspicua between samples of different years, 1920-1965

\begin{tabular}{lccc}
\hline \multicolumn{2}{c}{ succinea } & \multicolumn{2}{c}{ conspicua } \\
\hline $\mathrm{A}-\mathrm{B}$ & $.039 \pm .008$ & $\mathrm{~B}-\mathrm{A}$ & $.036 \pm .008$ \\
$\mathrm{~B}-\mathrm{C}$ & $.046 \pm .018$ & $\mathrm{C}-\mathrm{B}$ & $.011 \pm .017$ \\
$\mathrm{C}-\mathrm{D}$ & $.029 \pm .020$ & $\mathrm{D}-\mathrm{C}$ & $.047 \pm .020$ \\
$\mathrm{D}-\mathrm{F}$ & $.119 \pm .020$ & $\mathrm{~F}-\mathrm{D}$ & $.061 \pm .020$ \\
$\mathrm{E}-\mathrm{F}$ & $.114 \pm .035$ & $\mathrm{~F}-\mathrm{E}$ & $.060 \pm .033$ \\
\hline
\end{tabular}


A new material which may well represent the progeny of the previous Suwa materials was recently available. This is a hibernating population of the same beetle collected by Masuho Chino in 1964 and 1965 at the town Tatuno, $15 \sim 20 \mathrm{~km}$. south-west of Suwa. As may be seen in Table I, this new material indicates that the temporal variation in the pattern type frequencies had continued through the period 1954 to 1965 . As in the previous period, the change is most marked in the phenotype and gene frequencies of succinea and conspicua, while for spectabilis, a slight trend of increase of the phenotype and gene, but axyridis scarcely shows any such trend during the whole period extending over fifty years.

Cause of development of geographic and temporal gradients in the frequencies of genes for elytral patterns. Obviously, the geographic variation found in the frequencies of the pattern types of Harmonia distributed in Japanese islands, as well as in Continental China, conforms to Gloger's zoogeographic rule. It is admitted in this rule that this tendency is mainly due to the effect of climatic factors, primarily temperature and humidity.

According to Dobzhansky $(1933,1937)$, the original home of the species seems to be in west and central Siberia (Altai, Yenieisk), where the type axyridis is almost the only representative. A very few succinea, only $0.05 \%$, are found among his 4013 specimens from the Altai Mountains. It is likely that this type had appeared thereabout as a recessive mutant from axyridis. Perhaps owing to its hardiness in cold climate, succinea has increased to $74.5 \%$ at Khabarovsk, and to $85.6 \%$ at Vladivostok. Succinea also could become the predominant type of the species distributed in North China and Korea.

Spectabilis presumably appeared as a dominant mutant from axyridis, and conspicua in turn from spectabilis also as a dominant mutant. Owing to their melanic elytra, both, especially conspicua, are more fitted to warmer climate than axyridis and succinea, and the species could colonize Japanese islands via Sakhalin $\rightarrow$ Hokkaido, and extended its range through Honsyu to Kyusyu. The difference in composition between Kyusyu and Korean populations is too great to assume the colonization of the species across the strait between Korea and Japan, in spite of Ford's doubt (1964).

Kimura (1960) carried on a theoretical study of the data published in Komai's previous reports. He examined the data from view-points of migration and fitness of the populations in the localities that had provided the materials. He obtained results nicely conforming to his assumption.

The date of the temporal variation concerning elytral pattern 
types in Suwa-Tatuno population for the fitness and the rate of change of the relevant genes were examined according to the formulae:

$$
\begin{gathered}
s=\frac{1}{n}\left[\left(\frac{1}{q_{n}}-\frac{1}{q_{0}}\right)+\left(\log _{e} \frac{1-q_{n}}{q_{n}}-\log _{e} \frac{1-q_{0}}{q_{0}}\right)\right] \\
\Delta q=-s q^{2}(1-q) .
\end{gathered}
$$

where $s$ denotes the coefficient of selection, $q_{0}$ and $q_{n}$ the incidence of the recessive gene for succinea in the initial and the $n$th generation respectively, and e the base of natural logarism. The beetle is assumed to repeat four generations a year, in accordance with Hosino's observation. The results are shown in Table II.

Table II. The selection coefficient ( $s$ ) and the rate of change in frequency $(\Delta q)$ of the gene for succinea

\begin{tabular}{cccc}
\hline \multicolumn{1}{c}{ Period } & Generation & $s$ & $\Delta q$ \\
\hline $1920-1930$ & 40 & .00664 & -.00098 \\
$1930-1942$, '43 & 50 & .00646 & -.00094 \\
1942, ' $^{2}-1950$ & 30 & .00709 & -.00099 \\
$1950-1964$, '65 & 58 & .01740 & -.00232 \\
$1954-1964$, '65 & 42 & .02314 & -.00306 \\
\hline
\end{tabular}

The data in this table suggest a general trend in the temporal variation of $s$ and $\Delta q$ values. This trend seems to be correlated with the gradual change of the local climate, from the colder to the warmer. Regrettably, no exact climatological data for any regular climatic change at Suwa or neighbouring places for the past fifty years have been available. However, no one would possibly deny the fact of the temporal variation disclosed above and its relation to the local climate.

Obviously, the elytral pattern type represents a morphic character which is controlled by codominant pseudoalleles. The locus is probably heterotic in effect. Since the heterozygote combining conspicua and any other variety is practically conspicua in phenotype, and heterotic, this type is superior in fitness especially under warm climate. On the other hand, succinea has remained to be another predominant variety owing to its adaptability to cold climate. Evidently, such peculiarities have enabled the species to extend its range of distribution very widely in the Asiatic Continent and Japanese island chain, and from Siberia to South China. The distinct geographic and temporal gradients in the frequency of the elytral pattern types and the relevant genes probably have their background in this characteristic of the controlling locus. Furthermore, the temporal variation which was so distinct and rapid as to allow witness to one and the same observer is probably due to this state. 
Axyridis which is presumably the ancestral type of the species shows little variation either in geographic or temporal gradient, and always remained as the minority of the population, except in west Siberia. This is apparently owing to its lower fitness than conspicua and spectabilis in warm climate, and than succinea in cold climate.

Summary. As to the pattern types of the common polymorphic ladybeetle Harmonia axyridis Pallas, there is a distinct geographic gradient (cline) in their relative frequencies at each habitat in Japan, as well as in continental China. A distinct temporal variation (gradient) is found in population samples collected in different years from 1912 through 1965 at Suwa-Tatuno in Nagano Prefecture. These geographic and temporal gradients have probably developed in relation to the local climate, and have their genetic background on the composite and heterotic locus controlling the character.

\section{References}

Dobzhansky, Th. (1933): Geographical variation in lady-beetles. Amer. Nat., 67, 97-126.

(1937): Genetics and the Origin of Species. Columbia Univ. Press, New York.

Ford, E. B. (1964): Ecological Genetics. Methuen, London, etc.

Hosino, Y. (1940): Genetical studies on the pattern types of the ladybird beetle, Harmonia axyridis Pallas. J. Genet., 40, 215-225.

Huxley, J. S. (1955): Morphism and evolution. Heredity, 9, 1-52.

Kimura, M. (1960): Principles of Population Genetics (in Japanese). Baifukan, Tokyo.

Komai, T., M. Chino, and Y. Hosino (1950): Contributions to the evolutionary genetics of the lady-beetle, Harmonia. I. Geographic and temporal variations in the relative frequencies of the elytral pattern types and in the frequency of elytral ridges. Genetics, 35, 589-601.

Komai, T. (1954): An actual instance of microevolution observed in an insect population. Proc. Jap. Acad., 30, 970-975.

- (1956a): Population genetics of the lady-beetle, Harmonia axyridis (in Japanese with English Summary). Komai and Sakai eds. Syudan Idengaku Baifukan, Tokyo, 45-60.

- (1956b): Genetics of lady-beetles. M. Demerec ed. Adv. in Genet., 8, 155-188.

Tan, C. C. (1946): Mosaic dominance in the inheritance of color patterns in the ladybird beetle, Harmonia axyridis. Genetics, 31, 195-210. 